\section{Kidney \\ Blood Pressure Research}

\title{
A New PKD1 Mutation Discovered in a Chinese Family with Autosomal Polycystic Kidney Disease
}

\author{
Zhendi Wang ${ }^{\mathrm{a}, \mathrm{d}}$ Yang Wang ${ }^{\mathrm{b}, \mathrm{d}} \quad$ Jing Xiong \\ aDepartment of Urology; bepartment of Emergency; 'Department of Nephrology, Union Hospital, \\ Tongji Medical College, Huazhong University of Science $\&$ Technology, Wuhan, China, ${ }^{\mathrm{d} B o t h}$ authors \\ contributed equally to this work
}

\section{Key Words}

Autosomal polycystic kidney disease $\cdot$ PKD gene $\cdot$ Frame-shift mutation • Gene screening

\begin{abstract}
Background/Aims: Autosomal-dominant polycystic kidney disease (ADPKD), a heterogeneous genetic disorder characterized by massive kidney enlargement and progressive chronic kidney disease, is due to abnormal proliferation of renal tubular epithelium. ADPKD is known to be caused by mutations in PKD1 and PKD2 genes. Methods: In the present study, the mutation analysis of PKD genes was performed in a new Chinese family with ADPKD using Long-Range (LR) PCR sequencing and targeted next-generation sequencing (targeted DNA-HiSeq). Results: A unique 28 bp deletion (c.12605_12632del28) in exon 46 of the PKD1 gene was identified in two affected family members by LR PCR method, but not in any unaffected relatives or unrelated controls. Higher accuracy and less missing detection presented in LR PCR method compared with targeted DNA-HiSeq. This mutation c.12605_12632del28 (p.Arg4202ProextX146) resulted in a delayed termination of amino acid code, and was highly speculated pathogenic in this ADPKD family. Moreover, this newly identified frame-shift change was compared to the PKD gene database, but no similar mutation was yet reported. Conclusion: A novel frame-shift mutation, c. 12605_12632del28, in the PKD1 gene was found in a Chinese ADPKD family. All evidence available suggested that it might be the mutation responsible for the disease in that family.
\end{abstract}

Copyright (C) 2014 S. Karger AG, Basel

\section{Introduction}

Autosomal-dominant polycystic kidney disease (ADPKD) is a heterogeneous genetic disorder characterized by massive kidney enlargement and progressive chronic kidney disease, which is due to abnormal proliferation of renal tubular epithelium. The development 


\section{Kidney Blood Pressure Research}

of cysts is often found in the kidneys, but also present in other organs like liver, seminal vesicles, pancreas, and arachnoids membrane [1]. Approximately $50 \%$ of individuals with ADPKD have end-stage renal disease (ESRD) by the age of 60 years, which account for $\sim 5 \%$ of ESRD in North America [2-3]. ADPKD is the most common kidney disorder with a Mendelian inheritance pattern, and the prevalence ranges from 1/400 to 1/1000 worldwide [4]. However, the research in a large cohort in China is still absent.

$P K D 1$ and $P K D 2$, identified as causal genes for ADPKD, encode cell membrane proteins polycystin-1 (PC1) and polycystin-2 (PC2), respectively. PC1 interacts with PC2 to function as a cell surface signaling receptor as well as a mechano-sensor in renal primary cilia, which is involved in renal tubular differentiation pathways [5]. In linkage-characterized European populations, mutations in PKD1 and PKD2 account for $85 \%$ and $15 \%$ of cases with ADPKD, respectively [6]. However, more recent population-based series also suggest a relatively higher prevalence of PKD2 (ranging from 26 to 36\%) [7]. PKD1 patients have larger kidneys and earlier onset of ESRD compared with PKD2 patients (mean age with ESRD: 53.4 vs. 72.7 years) after adjustment of age and gender [8-11].

PKD1 is a large gene, containing 46 exons and an open reading frame of approximately $13 \mathrm{~kb}$, which encodes a protein with 4,302 amino acids. Particularly, the entire 5' region of PKD1 (up to exon 33) has been duplicated six times on chromosome 16 [2-3]. In contrast, $P K D 2$ is a single-copy gene containing 15 exons, encoding a protein with 968 amino acids [23]. So far, there are more than 500 and 200 mutations reported in the PKD1 and PKD2 genes, respectively, indicating a high level of allelic heterogeneity (Human Gene Mutation Database, HGMDR professional release, Cardiff; Polycystic Kidney Disease Mutation Database, PKDB, http://pkdb.mayo.edu). Most of these sequence variations result in truncation of the proteins and are unique to a single family [12].

Most recently, it has been reported that effective pharmacologic treatments for ADPKD patients may delay the onset of ESRD in PKD [13]. Therefore, it is important to make early and precise diagnosis of patients with ADPKD. However, clinical diagnostic results of ADPKD by traditional methods were often ambiguous, particularly for patients with an unclear renal phenotype, which makes the need for accurate genetic tests more compelling. Genetic testing of PKD1 is complicated because of the large transcript size and the complexity of the gene region. In this study, we used a novel mutation screening assay for PKD1 in a Chinese ADPKD family by directly sequencing long-range (LR) PCR products that cover the entire PKD1 gene. In the meantime, targeted next-generation sequencing (targeted DNA-HiSeq) was also used for comparison.

\section{Materials and Methods}

\section{Ethics statement}

This study was approved by the institution review board of Union Hospital, Tongji Medical College, Huazhong University of Science \& Technology. We initiated this research in accordance with the defined protocols. The design and performance of current study involving human subjects were clearly described. Written informed consent was obtained from all participants.

\section{Subjects}

The proband, a 50-year-old man, presented at nephrology outpatient clinic because of resistant hypertension, chronic flank pain and frequent macroscopic hematuria (Fig. 1). Physical examination found two abdominal masses at palpation of lateral quadrants. Serum creatinine level was $8.75 \mathrm{mg} / \mathrm{dL}$ with an estimated glomerular filtration rate (GFR) of $10.2 \mathrm{~mL} / \mathrm{min} / 1.73 \mathrm{~m}^{2}$. Serum hemoglobin was $89 \mathrm{~g} / \mathrm{L}$. Renal ultrasound examination showed bilateral enlarged kidneys with multiple cysts of variable sizes. Cysts 


\section{Kidney Blood Pressure Research}

Table 1. PKD1 Primers for LR PCR

\begin{tabular}{llcc}
\hline Fragment & Primer sequence $\left(5^{\prime}-3^{\prime}\right)$ & Temp. $\left({ }^{\circ} \mathrm{C}\right)$ & Size $(\mathrm{bp})$ \\
\hline Exon 1 & CGCAGCCTTACCATCCACCT & 64 & 2278 \\
Exon 2-7 & CCCCGAGTAGCTGGAACTACAGTTACACACT & 70 & 4041 \\
Exon 8-12 & ACGTCTGCGAGCTGCAGCCC & 70 & 3893 \\
Exon 13-15 & TGGAGGGAGGGACGCCAATC & 65 & 4391 \\
Exon 15-21 & ATCCCTGGGGGTCCTACCATCTCTTA & 68 & 5253 \\
Exon 22-26 & ATGCTTAGTGAGGAGGCTGTGGGGGTCCA & 70 & 3276 \\
Exon 27-34 & CGGGTCACCGGTTGTGGCA & 70 & 3916 \\
Exon 35-41 & CAAGAGGCTCAAGAAACTGCCCG & 68 & 2632 \\
Exon 42-46 & GAGTAGTTCTCCAGGAGTGCCG & 63 & 2370 \\
\hline
\end{tabular}

were also found in both livers. The diagnosis of ADPKD was established and a genetic conformation was recommended. Moreover, the hereditary pedigree was further investigated.

\section{Mutation analysis}

Genomic DNA was extracted from peripheral blood lymphocytes using standard DNA extraction methods. Due to the complexity of the PKD1 gene, we used a novel LR PCR plus directly sequencing assay in PKD1 mutation screening in this study, which was confirmed to be more sensitive, specific and accurate compared with other analysis system such as SURVEYOR-WAVE method. The LR PCR was performed as previously described with minor modification [14]. Briefly, the entire coding region (5' and 3' untranslated regions, and exon-intron boundaries of PKD1) were amplified in nine distinct LR PCRs (Gene1, Gene2-7, Gene8-12, Gene13-15, Gene15-21, Gene22-26, Gene27-34, Gene35-41, and Gene42-46), using PCR primers (Table 1) anchored in either the rare mismatched region with the HGs or the single-copy region of PKD1. The details for amplification, purification and sequence analysis of LR PCR products were referenced as described by Tan et al [14].

Meanwhile, targeted DNA-HiSeq was also performed. A custom capture array (NimbleGen, Roche) was designed to capture all exons (3093), splice sites and the immediately adjacent intron sequences of 222 genes involved in more than 100 different genetic diseases, including ADPKD [15]. Target DNA capture, enrichment and elution were performed as previously described [15]. The potential disease-causing mutations identified were further confirmed by PCR and sequence analyses in the proband and his family (Fig. 1). In addition, for PKD2, all 15 exons including adjacent 30-50 bp intronic sequence were directly amplified by PCR. Primers flanking 15 exons of PKD2 gene were designed from genomic sequence (GenBank Acc. No. NT_016354) using the program PRIMER3 (http://zeon.well.ox.ac.uk/git-bin/primer3_www.cgi). The details for direct sequencing and data analysis performed were described previously [16].

\section{Results}

\section{Pedigree investigation}

The family history was further investigated after the proband was diagnosed with ADPKD. His father died 10 years ago because of uremia. Unfortunately, no special examinations were performed and the actual etiology of renal failure was unclear. The proband has no children, but he has a brother two years older than him. The proband's brother was suggested to do relevant examination, and the results showed that he had the same disease and his blood creatinine had increased to $2.26 \mathrm{mg} / \mathrm{dL}$ without obvious symptoms and signs. The proband's brother has a 20-year-old son and he refused to do the examinations relevant to ADPKD. The proband's mother is healthy to date. So we speculated that these two brothers' disease was inherited from their father, and the pedigree drawing was showed in the Fig. 1. 


\section{Kidney Blood Pressure Research}

\section{Identification of the pathogenic PKD1 and PKD2 mutations}

The Blood samples were collected from the proband, his elder brother, his mother and healthy controls. Total genomic DNA from whole blood was extracted according to the manufacturer's standard procedure using the QIAamp DNA Blood Midi Kit (Qiagen, Hilden, Germany).

Using targeted DNA-HiSeq, no large deletion or duplication was found in either PKD1 or PKD2 gene. Only one missense change (p. Lys4151Thr) was detected in the coding region of $P K D 1$, which was a known polymorphism in the $P K D$ gene mutation database. No sequence variants including frame-shift, nonsense, missense, or shear variants were detected in PKD2 gene. The quality report chart was showed in the Fig. 2, the extron sequencing coverage reached more than 99\% except the first, 2, 11, 42 exon of the $P K D 1$ gene and the first exon of $P K D 2$ gene. The mean sequencing depth of every exon was quite close to the median depth, which indicates the randomness of sequencing was good.

Using LR PCR method, the missense change (p.Lys4151Thr) was also found in the coding region of PKD1 (Fig. 3A). Moreover, a frame-shift mutation c.12605_12632del28 (p.Arg4202ProextX146) was detected in exon 46 of PKD1 gene (Fig. 3B). This frame-shift variant induces a delayed termination of amino acid code, which is probably pathogenic, although no related reports of this mutation have been found before. The result indicates that LR PCR method is more accurate and comprehensive in PKD1 gene screening compared with targeted DNA-HiSeq. However, LR PCR method is expensive, complex, and highly labor intensive, which hinders the usage of LR PCR in routine clinical practices.

In addition, the same frame-shift mutation (c. 12605_12632del28) was found in the DNA sample of the proband's brother, and no gene mutations were found in the blood sample of their mother and healthy controls (Fig. 3B). Thus, this frame-shift mutation was highly speculated as the pathogenic mutation in this ADPKD family.

\section{Discussion}

ADPKD is an important inherited nephropathy with high prevalence. The clinical significance of genetic testing in ADPKD is well established. However, PKD1 lies in a complex region that is duplicated six times on chromosome 16. The presence of these highly homologous pseudogenes has made genetic analysis of PKD1 challenging, thereby discrimination of these pseudogenes from PKD1 requires locus-specific amplification methods. Although some researchers performed denaturing high-performance liquid chromatography (DHPLC) and polymerase chain reaction-single-strand conformation polymorphism (PCR-SSCP) to screen mutations in ADPKD for research and clinical purposes [17-18], direct sequencing is considered to be a better choice [18]. Recently, Tan et al proposed a novel LR PCR Sequencing Method [14]. By using this tool, the entire PKD1 coding region was amplified by nine reactions, which generated product sizes from 2 to $6 \mathrm{~kb}$ and circumvented the needs for specific PCR amplification of individual exons. In the present 


\section{Kidney Bloód Pressure Research}

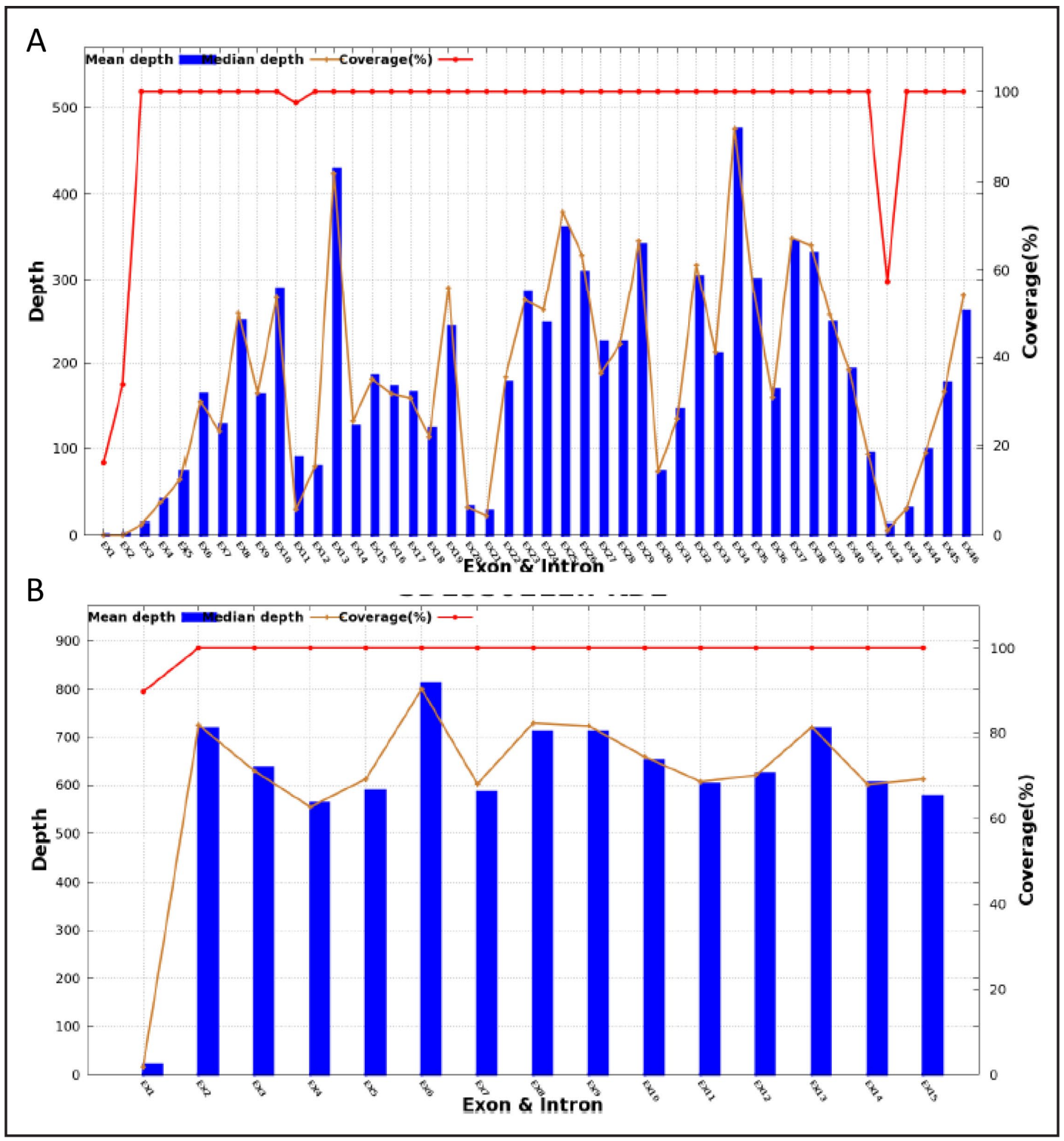

Fig. 2. Variation identified by targeted DNA-HiSeq method. Panel A: PKD1 gene. Panel B: PKD2 gene. The quality report chart shows the sequencing coverage reached more than $99 \%$ except the first, 2, 11, 42 exon of the PKD1 gene and the first exon of PKD2 gene. The mean sequencing depth of every exon was quite close to the median depth.

study, we use both LR PCR and targeted DNA-HiSeq to locus specific mutations of PKD1 gene, and higher accuracy and less missing detection presented in the LR PCR method.

To date, over 600 of different mutations have been reported in PKD1 and PKD2 gene, however, their pathogenic consequences remains unclear, which has created a major difficulty or uncertainty for clinical use. Therefore, for clinical practice, it is very important to know whether an observed mutation is pathogenic or not. To this end, all the identified variations need to be carefully studied, especially when no other family member is available for segregation analysis. In our study, the mutation analysis in this ADPKD family identified a 


\section{Kidney \\ Blood Pressure Research}

Fig. 3. Variation identified of the proband by LR PCR method. Panel A shows a missense change (p. Lys$4151 \mathrm{Thr}$ ) in the coding region of PKD1. Panel $B$ shows a frame-shift mutation c. 1260512632del28 (p. Arg 4202 ProextX146) in exon 46 of PKD1.

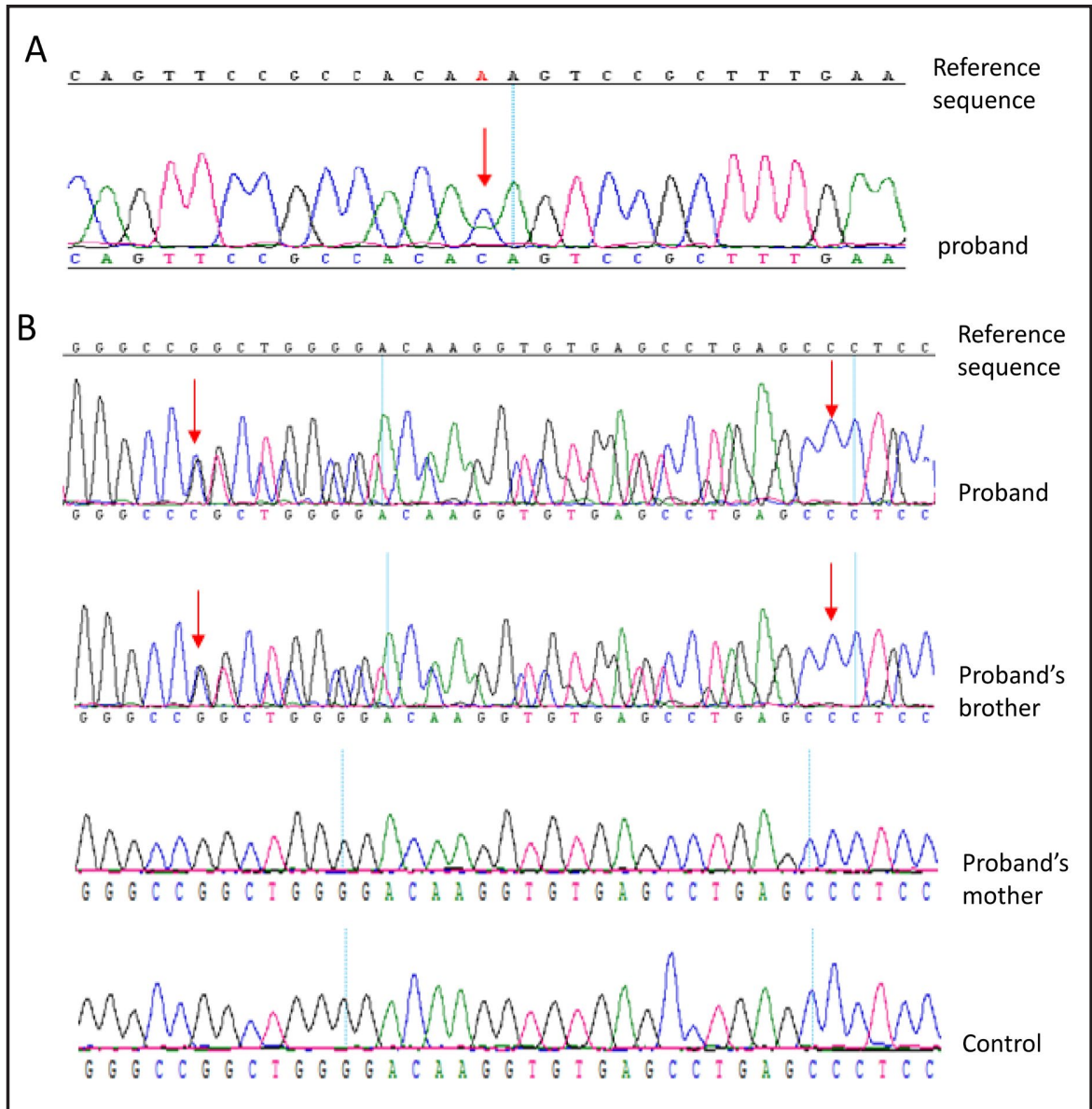

previously undescribed mutation in PKD1 gene. This mutation results in a frame-shift variant c.12605_12632del28 (p.Arg4202ProextX146) in exon 46, leading to a delayed termination of amino acid code. In general, protein-truncating (because of frame-shift deletion/ insertion, nonsense changes, or splice defects) mutations are considered to be pathogenic. This deletion is predicted to produce a mutant polycystin protein with a frame-shift of its $\mathrm{C}$ terminal and 146 amino acids longer than the wild-type protein due to a delayed termination codon. Therefore, it does not produce a new protein, but only the C-terminal of the PKD1 is changed. This mutation has never been reported before, and no similar frame-shift PKD1 gene mutations were published. Several published studies have demonstrated that large genomic deletions in the PKD1 gene are relatively rare with a frequency of $\sim 4 \%$ [19-20]. Further in vitro and in vivo functional studies are needed to confirm the pathogenicity of Arg4202ProextX146. So far, multiple mutations in PKD1 and PKD2 genes have been identified, however, the genotype-phenotype relationship of these mutations with ADPKD remains largely unknown. Recent studies reported that renal survival associated with PKD2 mutations was approximately 20 years longer than that associated with PKD1 mutations. The median age at onset of ESRD was 58 years for PKD1 mutation carriers and 79 years for PKD2 mutation carriers [21]. Moreover, Dedoussis et al. found that PKD patients with both PKD1 mutations and PKD2 mutations might have a more severe phenotype than those with only PKD1 mutations [22]. Our finding of the new mutation in PKD1 will contribute to understand the genotype-phenotype correlation in future studies. 


\section{Kidney \\ Blood Pressure Research}

Kidney Blood Press Res 2014;39:1-8

DOI: $10.1159 / 000355772$

Publisned oninne: April 30, 2014

(C) 2014 S. Karger AG, Base

www.karger.com/kbr

Wang/Wang/Xiong: A new PKD1 mutation in an ADPKD family

\section{Conclusions}

Our study has found a novel unique 28 bp deletion, c. 12605_12632del28, in the PKD1 gene in a Chinese ADPKD family. All evidence available suggest that it might be the mutation causing the disease in this family. For patients with ADPKD, direct gene diagnosis and prenatal diagnosis in clinical practice would be helpful.

\section{Disclosure Statement}

The authors declare that there are no conflicts of interest.

\section{Acknowledgement}

This work was supported by National Natural Science Foundation of China (30800532) and New Teachers' Fund for Doctor Stations, Ministry of Education (200804871122). The authors declare that the results presented in this paper have not been published previously in whole or part, and there are no conflicts of interest.

\section{References}

1 Torres VE, Harris PC, Pirson Y: Autosomal dominant polycystic kidney disease. Lancet 2007;369:12871301.

-2 Igarashi P, Somlo S: Genetics and pathogenesis of polycystic kidney disease. J Am Soc Nephrol 2002;13:2384-2398.

7 Ong AC, Harris PC: Molecular pathogenesis of ADPKD: The polycystin complex gets complex. Kidney Int 2005;67:1234-1247.

4 Dalgaard OZ, Norby S: Autosomal dominant polycystic kidney disease in the 1980's. Clin Genet 1989;36:320-325.

5 Polycystic kidney disease: The complete structure of the PKD1 gene and its protein. The international polycystic kidney disease consortium. Cell 1995;81:289-298.

6 Peters DJ, Sandkuijl LA: Genetic heterogeneity of polycystic kidney disease in europe. Contrib Nephrol 1992;97:128-139.

7 Pei Y, Watnick T: Diagnosis and screening of autosomal dominant polycystic kidney disease. Adv Chronic Kidney Dis 2010;17:140-152.

-8 Hateboer N, v Dijk MA, Bogdanova N, Coto E, Saggar-Malik AK, San Millan JL, Torra R, Breuning M, Ravine D: Comparison of phenotypes of polycystic kidney disease types 1 and 2. European PKD1-PKD2 study group. Lancet 1999;353:103-107.

-9 Harris PC, Bae KT, Rossetti S, Torres VE, Grantham JJ, Chapman AB, Guay-Woodford LM, King BF, Wetzel LH, Baumgarten DA, Kenney PJ, Consugar M, Klahr S, Bennett WM, Meyers CM, Zhang QJ, Thompson PA, Zhu F, Miller JP: Cyst number but not the rate of cystic growth is associated with the mutated gene in autosomal dominant polycystic kidney disease. J Am Soc Nephrol 2006;17:3013-3019.

10 Rossetti S, Burton S, Strmecki L, Pond GR, San Millan JL, Zerres K, Barratt TM, Ozen S, Torres VE, Bergstralh EJ, Winearls CG, Harris PC: The position of the polycystic kidney disease 1 (PKD1) gene mutation correlates with the severity of renal disease. J Am Soc Nephrol 2002;13:1230-1237.

-11 Magistroni R, He N, Wang K, Andrew R, Johnson A, Gabow P, Dicks E, Parfrey P, Torra R, San-Millan JL, Coto E, Van Dijk M, Breuning M, Peters D, Bogdanova N, Ligabue G, Albertazzi A, Hateboer N, Demetriou K, Pierides A, Deltas C, St George-Hyslop P, Ravine D, Pei Y: Genotype-renal function correlation in type 2 autosomal dominant polycystic kidney disease. J Am Soc Nephrol 2003;14:1164-1174. 


\section{Kidney \\ Blood Pressure Research}

\section{Kidney Blood Press Res 2014;39:1-8}

DOI: $10.1159 / 000355772$

Published oninne: April 30, 2014

(C) 2014 S. Karger AG, Base

www.karger.com/kbr

Wang/Wang/Xiong: A new PKD1 mutation in an ADPKD family

12 Rossetti S, Consugar MB, Chapman AB, Torres VE, Guay-Woodford LM, Grantham JJ, Bennett WM, Meyers CM, Walker DL, Bae K, Zhang QJ, Thompson PA, Miller JP, Harris PC: Comprehensive molecular diagnostics in autosomal dominant polycystic kidney disease. J Am Soc Nephrol 2007;18:2143-2160.

13 Aihara M, Fujiki H, Mizuguchi H, Hattori K, Ohmoto K, Ishikawa M, Nagano K, Yamamura Y: Tolvaptan delays the onset of end-stage renal disease in a polycystic kidney disease model by suppressing the increases in kidney volume and renal injury. J Pharmacol Exp Ther 2014;349:258-267.

-14 Tan YC, Michaeel A, Blumenfeld J, Donahue S, Parker T, Levine D, Rennert H: A novel long-range pcr sequencing method for genetic analysis of the entire PKD1 gene. J Mol Diagn 2012;14:305-313.

-15 Wei X, Ju X, Yi X, Zhu Q, Qu N, Liu T, Chen Y, Jiang H, Yang G, Zhen R, Lan Z, Qi M, Wang J, Yang Y, Chu Y, Li X, Guang $Y$, Huang J: Identification of sequence variants in genetic disease-causing genes using targeted nextgeneration sequencing. PLoS One 2011;6:e29500.

-16 Hoefele J, Mayer K, Scholz M, Klein HG: Novel PKD1 and PKD2 mutations in autosomal dominant polycystic kidney disease (adpkd). Nephrol Dial Transplant 2011;26:2181-2188.

17 Yu C, Yang Y, Zou L, Hu Z, Li J, Liu Y, Ma Y, Ma M, Su D, Zhang S: Identification of novel mutations in chinese hans with autosomal dominant polycystic kidney disease. BMC Med Genet 2011;12:164.

18 Ding L, Zhang S, Qiu W, Xiao C, Wu S, Zhang G, Cheng L: Novel mutations of PKD1 gene in chinese patients with autosomal dominant polycystic kidney disease. Nephrol Dial Transplant 2002;17:75-80.

19 Ariyurek Y, Lantinga-van Leeuwen I, Spruit L, Ravine D, Breuning MH, Peters DJ: Large deletions in the polycystic kidney disease 1 (PKD1) gene. Hum Mutat 2004;23:99.

20 Consugar MB, Wong WC, Lundquist PA, Rossetti S, Kubly VJ, Walker DL, Rangel LJ, Aspinwall R, Niaudet WP, Ozen S, David A, Velinov M, Bergstralh EJ, Bae KT, Chapman AB, Guay-Woodford LM, Grantham JJ, Torres VE, Sampson JR, Dawson BD, Harris PC: Characterization of large rearrangements in autosomal dominant polycystic kidney disease and the PKD1/TSC2 contiguous gene syndrome. Kidney Int 2008;74:1468-1479.

-21 Cornec-Le Gall E, Audrezet MP, Chen JM, Hourmant M, Morin MP, Perrichot R, Charasse C, Whebe B, Renaudineau E, Jousset P, Guillodo MP, Grall-Jezequel A, Saliou P, Ferec C, Le Meur Y: Type of PKD1 mutation influences renal outcome in ADPKD. J Am Soc Nephrol 2013;24:1006-1013.

-22 Dedoussis GV, Luo Y, Starremans P, Rossetti S, Ramos AJ, Cantiello HF, Katsareli E, Ziroyannis P, Lamnissou K, Harris PC, Zhou J: Co-inheritance of a PKD1 mutation and homozygous PKD2 variant: A potential modifier in autosomal dominant polycystic kidney disease. Eur J Clin Invest 2008;38:180-190. 